\title{
Cross-Cousin Marriages in Kishtwar
}

\author{
Gopal Krishan Sharma \\ Department of Sociology, University of Jammu, Jammu and Kashmir, India \\ E-Mail: Sgopal209@gmail.com
}

\begin{abstract}
Marriage is a social combination or lawful contract between the general population that makes family relationship and its definition fluctuates as indicated by various societies. Marriage and Kinship are the essential unavoidable truths that apply to everyone of any person. The present paper is about the Kinship and Marriage structure among the Hindu people group in the Kishtwar District. The investigation has explicitly investigated the act of cross-cousin relational unions among the network and has endeavoured to investigate the different family relationship ties predominant among them. This paper is an attempt to investigate the family relationship and marriage structure among the Hindu people group in Kishtwar. The paper likewise accomplishes to investigate the different types of cross-cousin marriages among the Hindu people group in Kishtwar.

Keywords: Marriage, Kinship, Affinity, Consanguinity, CrossCousin Marriage
\end{abstract}

\section{INTRODUCTION}

Kishtwar is a district of Jammu and Kashmir state in the North-west India with population 2, 31,037 [1]. Kishtwar is bounded by Zanskar in north, Himachal Pradesh in the east, Doda and Bhaderwah on the south and Anantnagand Banihal on the west. Kishtwar, the upland valley in the north-east corner of Jammu region, lies ensconced among the picturesque folds of the PirPanjal and the Great Himalayan Ranges. Society is largely agriculture based, thus making it simple in nature. The villages of the region were largely self-sufficient earlier but this is getting eroded by the passage of time. One can see that the solidarity of the villages is gradually shifting from mechanical solidarity to the organic solidarity. As change is inevitable, the society also exhibits a kind of transition. Modernity is now reaching slowly and gradually and its impact is visible in all spheres of life. This also resulted in change from joint family system towards nuclear family. The lineage is traced through male line and girls do not inherit parental property. Consanguinal relations and relatives occupy more importance than affinal relations and relatives. Marriages are mostly performed and preferred between the known ones. The most preferred alliance for marriage is cross-cousins. Both matrilateral and patrilateral type of cross-cousin marriages are practiced. Different caste groups comprise the Hindu society of Kishtwar. Main castes which are present are Brahmins, Mahajans, S.C and Rajputs. Practice of marriage with crosscousins is almost present in all castes both in the rural as well as urban areas. This paper has explored the degree of prevalence of cross-cousin marriages among different caste groups both at the rural as well as urban level.
Mate selection in Hindu society is bound with the ideas of endogamy, exogamy and hypergamy. Endogamy is a social decide that requires a man to choose the life partner from the caste and sub-caste; exogamy prohibits selection from the same gotra and sapindas. Kane [2] in his History of Dharamshastras, has kept up that exogamous prohibitions were forced for avoiding transmission of family defects through heredity and for the fear that there might be subsequent loss of morals. These arguments are not acknowledged today for the reasons that decay of genealogy isn't accounted for among the non-Hindu people group who practice cross-cousin marriages. Kapadia [3] has said that the rule of spinda-exogamy remained significant till eighth century. Today, however this rule is followed all around by all Hindus, yet the instances of cousin marriages are not unknown. Among Hindus of North India, there is avoidance of a consanguineous union, but Kishtwar shows an exception where cross-cousin marriages are practiced by Hindus in urban as well as in rural areas.

Levi-Strauss in his "Elementary structures of kinship" [4] has focussed on the categories of individuals which are considered as marriage able and non-marriageable groups. The marriageable category may include cross-cousins. Marriage systems can be reciprocating when two groups exchange women; they can be circular when a large number of groups intermarry and, on balance, each group receives as many women for wives, as it gives out women in marriage to other groups; they can be asymmetrical when certain group give out significantly more women in marriage than they receive, while other groups receive more women than they give [5]. Union between two individuals who are related as second cousins or closer is called as consanguineous marriage [6]. Consanguineous marriages i.e. marriage with parallel cousins as well as with crosscousins is practiced by different communities of the country. This paper has attempted to study and understand the practice of cross-cousin marriages among the Hindus in Kishtwar district and also the kinship and marriage structure in the said area. It has also explored the different forms and rules of cross-cousin marriages. The practice of crosscousin marriages was seen both in the rural and urban sectors in order to analyse its prevalence.

\section{REVIEW OF LITERATURE}

In this section only those studies are considered which are very informative and of great significance and will provide the researcher a guide line for the present work. This 
includes consultation of books, journals and online articles/data available on the web. Review of literature has been undertaken to discuss the problem stated above and to understand various concepts like marriage, kinship, type and forms of marriages etc.

Madan and Majumdar (2002) in their work 'An Introduction to Social Anthropology' have rightly traced the evolution of the marriage institution. They see the evolution in the unilinear way i.e. in a straight line where at the lower end they put promiscuity and monogamy at the top end. Madan and Majumdar argue that there are the coeval with each other and with culture because without family there would be no preservation of culture and species and without marriage there would be no family. Referring on the forms of marriage, they have argued that there are several types of marriages and we come across certain rules lying down prohibitions, preferences and prescriptions in deciding the form of marriage.

T.N.Madan (1989) in his book 'Family and Kinship: A study of Pandits in Rural Kashmir' has written about his study in the villages of Kashmir that are, Utrassu and Umanagri. This book provides a deeper insight about the social organisation and family patterns of the people of the respective villages. Madan has also worked on the marriages and its types which were prevalent among the natives of the villages. He has also taken the wider kinship structure of the people into consideration. All the areas which Madan has studied are of great significance for the present research. This book was very useful for the present research to understand the methodological framework and to have an understanding on symmetrical and asymmetrical exchanges.

A.C. Mayer (1960) in his book 'Caste and Kinship in Central India' has made a study of Ramkhedi village of Malwa. He has described the primary and secondary kin of the village families. The primary kin consist of mother, father, brother and sister whereas marital kin such as brother's wife, mother-in-law and others. Mayer's study describes only the kin found in a, patriarchal descent group. The book has helped the researcher to have an understanding on primary and secondary kin.

In her study, 'Kinship Organization in India' Karve (1953) has conducted fieldwork in four regions of the countryNorthern, Central, Southern and Eastern. In this study she differentiates kinship systems from the perspective of geography and language. Karvehas, in a broad way, studied two basic systems of kinship. These two divisions are inclusive of tribals of Southern and Eastern parts of India. These divisions also take into consideration both the matriarchal and patriarchal descent groups.

In their joint work 'Marriage and Family in Diverse and Changing Scenario' Ratra, Kour and Chikara (2006) have explained all the concepts related to marriage. This book traces the evolution of marriage from the historical part to the present day. The book provides insight to the physical, mental and sexual readiness for marriage and mate selection. This book gives a detailed explanation about the theories of marriage and family like symbolic interaction theory, structural functional theory, conflict theory, family systems theory. This book contains exhaustive detailed description of the marriage customs of more than 50 Indian societies. Talking about the types of marriage in Indian context, the authors have given a detailed explanation of eight types of marriage as Brahma, Daiva, Arsha, Prajapatya, Gandharva, Asura, Rakshasa, and Paishacha.

\section{METHODOLOGY}

Thepresent study has used exploratory and descriptive research designs. Exploratory research method was used to explore and find out the genesis of the cross-cousin marriage in Kishtwar. Descriptive method was used to describe their socio-economic life, their living and their working conditions. Exploratory research method was used to investigate and find out the origin of the cross-cousin marriage in Kishtwar.

Present study has also made use of the structured interview schedule in which a set of questions were prepared to seek the answers. Before finalizing the interview schedule, a pilot study was conducted to be acquainted with about the loopholes left in construction of the Interview schedule. Interview Schedule which consisted of both the open and closed ended questions was used for gathering information. Interview schedule is the finest way to find out useful, accurate information effectively. It is a research tool or an instrument for collecting data whereas interviewing is a method of data collection. It is comprised of a list of questions that researcher asks the interviewee, with followup questions which need respondents to answer in their own words. On the other hand, closed ended questions are the fixed choice questions. They necessitate the respondent to choose a response from the options provided by the researcher [7].

In the present study, the data was collected from both primary and secondary sources. The primary data collection was done through the field work in which interviews were conducted with the help of interview schedule along with the non-participant observation method. The observation method is the largely used method especially in studies relating to behavioural sciences. In a way we all observe things around us, but this sort of observation cannot be considered as not scientific observation. Observation becomes the method of data collection and a scientific tool for the researcher, when it provides a formulated research purpose. It is systematically planned and recorded and is subjected to have a check and control on validity and reliability. Under the method of observation, the information is sought by mode of investigator's own direct information without asking the respondent. When the observer observes by making himself a member of group, he is observing so that he can experience what the members 
of the group experiencing, then the observation is considered as the participant observation. But when the observer observes as a detached representative without his personal participation to experience through participation what others experience, the observation of this type is often termed as non-participant observation [8].

In-depth interviews and narratives of the respondents were collected which provided insights about the process of cross-cousin marriage. The interview method of collecting data involves presentation of oral-verbal stimuli and reply in terms of oral-verbal responses. This method can be used through personal interviews in which the interviewer ask questions generally in a face to face contact to the other person or persons. This type of interview may be in the form of direct personal investigation or it may be indirect oral investigation. Interview method is most suitable for intensive investigation. The universe of study was comprised of Kishtwar district from where a sample of 200 respondents was taken. Sample was then bifurcated where 100 respondents from the rural and 100 from the urban area comprised the sample. Sampling frame reduces the number of total population and gives the target population" [9].Quota sampling method was employed to draw the sample. In the present research, respondents from different castes were selected accordingly as per the quota fixed. The secondary sources for the study which were taken included various books, official data, census, documents, reports, newspapers, articles, and journals that were utilized for getting better insight about the research problem [10].

\section{FINDINGS AND RESULTS OF THE STUDY}

1. Different caste groups were studied in both rural as well as urban setting. Although, respondents of the study belonged to different age group. A maximum number of respondents belonged to the age group of 46-65 years. This particular age group was chosen for interview with an objective to find out the discourse about the above said practice. For the data collection head of the family was interviewed.

2. In the study it was found that very few households were headed by the females and that too, due to some unavoidable and unique conditions like ownership of property, death of husband etc.

3. Majority of the respondents were males and there where were a less number of females who participated and responded to the researcher. As the responses were sought from the head of the family, so they comprised of maximum number.

4. Women were taken into consideration where males were not present and in most of the cases, the other male members (though not senior than female) responded and females avoided to interact.

5. The percentage of female headed families in rural area was less when compared with the percentage of female respondents of the urban area. Reasons for the less participation of females in rural area can be because of less awareness, low educational status and high rigidity towards traditional outlook. It is clear that the patriarchy is rigid in the said area because lesser number of females interacted with the researcher.

6. Regarding the educational level of the respondents, it was found that maximum numbers of respondents were educated and a very minimal percentage of the respondents comprised of illiterate respondents.

7. Data shows that the literacy rate in Kishtwar is quite good which is also supported by the Census report, 2011. Education of respondents in rural and urban areas shows that in rural sector illiterate respondents were more than the urban sector.

8. Marriage outside caste group is not accepted although the rigidity of caste endogamy is now weakening and some incidences of intercaste marriages have been witnessed over the time. Besides this, marriage with a Muslim is permanently condemned. Marriage is performed outside one's own gotra as the members of the same gotra are considered as the descendents of the same ancestor. A man's gotra is considered as the name of his father or other male agnates, but in case of a married woman, she belongs to her husband's gotra. Membership to a gotra is acquired by a boy at the time of ritual initiation and by girls at the time of marriage, entails no other mutual rights and obligations between the members except that they shall not enter into marital alliances.

9. Data interpretation regarding the relation of crosscousin marriages show an increase in the cases of crosscousin marriages among the respondents who were educated up to higher secondary level. This shows that education has less impact on the traditional culture and indicates the continuity of the practice but among those who have opted for higher education like graduation and other higher degrees, the incidences of cross-cousin marriages were reported less which indicates the changing nature of the practice of cross-cousin marriage.

10. It was found that among all the occupational groups, the practice of cross-cousin marriage was present but with the varying percentages. No class or occupational group under study was found in which this practice was totally absent.

11. Variations in the percentage of cross-cousin marriages in the occupational groups show that private sector and agricultural group have a maximum percentage of cross-cousin marriages whereas government sector shows a least number of cross-cousin marriages. This can be because of the reason that those serving in government jobs are more likely to get in contact with other cultures also which contributes in the change in their choices and preferences for marriage.

12. In the area under study, cross-cousins are looked as the desired marriage partners although the scenario is getting changed with contact with outer cultures and due to modernisation processes. Out of the total respondents interviewed, maximum were married to their cross-cousins. 
13. Those who were married with other than cross-cousins, maximum of them argued that the prominent reason for having a spouse other than cross-cousin was the nonavailability of the cross-cousin from the kinship organization. Change in the preferences and choice of mate selection is not rapid and is slowly changing the marital choices.

14. A slight difference was observed in the percentage of cross-cousins marriages in the ego's generation in rural and urban areas. It was found that rural sector has witnessed more consanguineous marriages than the urban sector. This is due to the reason that the rural areas are characterized by the strong hold with the traditions and cultures.

15. Respondents which show a greater number of crosscousin marriages argue that the consanguineous marriages promote in-group solidarity, keep women in a better condition as the marriage within a familiar group help them to adjust more and also help to keep the property intact within the group. Studies on the consanguineous marriages also suggest some similar type of explanations regarding the higher prevalence of cross-cousin marriages.

16. It was found that both matrilateral and patrilateral types of cross-cousin marriages were found among the respondents in Kishtwar but the number of patrilateral type of cross-cousin marriages was quite less than matrilateral cross-cousin marriages. Data shows that majority of respondents have done matrilateral type of cross-cousin marriage.

17. Data suggests that the most preferred form of crosscousin marriage is with the MBD-FZS (matrilateral) and FSD-MBS (patrilateral) type of cross-cousin marriage is less preferred.

18. Different opinions and explanations regarding the less number of patrilateral cross-cousin marriages were noted during the interaction with respondents. Those who were favouring and had done patrilateral crosscousin marriage gave the gotra -explanation. They were of the view that in Hinduism gotra-exogamy is a rule and anyone outside the gotra can become a marriageable partner. Although, father's sister (FZ) and father's sister's daughter (FZD) belong to a different gotra, so it is permissible to marry in that kin group. Those respondents who were favouring matrilateral cross-cousins over patrilateral ones for marriage suggest the theory of blood. They argue that father's sister is closer in blood line to which father belongs. Therefore to avoid marriage within close blood relations, patrilateral type of cross cousin marriages are less preferred. Some suggests that patrilateral type of cross-cousin marriages shrinks the kin group whereas matrilateral type of cross-cousin marriages expands the kinship circle.

19. It was found that matrilateral cross-cousin marriages are the prescriptive marriages in Kishtwar as there is the presence of preferential matrilateral cross-cousin marriages and prohibited patrilateral cross-cousin marriage. All caste groups in both the sectors show almost an equal percentage of matrilateral type of cross-cousin marriages.

20. A minimal difference between the rate of cross-cousin marriages between the ego's generation and ego's parental generation was observed. It was found from the responses of the respondents that the reason for this continuity in cases of cross-cousin marriages in ego's generation in Kishtwar is because of arranged nature of marriages and the outlook of the people towards traditional choices. Marriages were mostly arranged and the preferred marriage partner was chosen from the marriageable kin group. To follow the ongoing culture of cross-cousin marriages, parents of the generation of ego used to arrange the marriages with in the crosscousin category.

21. In the parental generation, both rural and urban sector shows the variation in the cases of cross-cousin marriages. Rural sector show a majority of cross-cousin marriages whereas in urban area cases of cross-cousin marriages were recorded quite less than the parental generation of ego.

22. The Increasing trend of cross-cousin marriages at intergenerational level suggests that there is strong hold towards the traditions and culture among the people in Kishtwar, which contributes towards the continuity of the practice of cross-cousin marriages.

23. Regarding the choice of marriage, it was found that minimal respondents were exclusively favouring affinal marriages where as a majority of respondents were in favour of consanguineous marriages. Besides this, there were some respondents who were indefinite about the choice of mate selection and were favouring of both the types.

24. The reasons for the preference of consanguineous marriages are primarily social. The communities which favour the consanguineous marriages, there is a higher compatibility between husband and wife who share the same social relationships after marriage as before marriage, as well as the compatibility between the couple and other family members. Respondents who were in favour of consanguineous marriages argue that these type of marriages are more favourable for the women's status, including the wife's better relationship with her in-laws who could support her in time of need. It was also found that in consanguineous marriage alliances premarital negotiations regarding financial matters of marriage are more easily conducted and sometimes less costly. Wife's parents prefer to have their daughter living near them and to enjoy the presence of their grandchildren. Moreover, wealthy landlords may prefer to keep their property within the family.

25. Those who were against the cross cousin marriages and were exclusively favouring the affinal marriages argued that there are negative impact of consanguineous marriage in terms of increased genetic risks to the offspring, as opposed to the potential social and economic benefits. 
26. Regarding type of kinship terminology, it was found that a majority of respondents were using both (Classificatory and Descriptive) type of kin terms to designate the members of kin group. A minimal number of respondents were using classificatory kinship terminology. None of the respondents were exclusively using descriptive terms. On the further examination of data among different caste groups, it was observed that all caste groups with almost an equal percentage were using classificatory kinship terminology. Similarly, all caste groups in equal proportions were using both the types of kinship terminology.

27. Regarding the changing nature of kinship terminology, responses were sought from the respondents and it was found that out of the total sample, maximum respondents were of the view that there is change in the kinship terminology. Further examination of data in rural and urban sectors suggests that urban sector is witnessing more change in the kinship terminology than the rural sector.

\section{CONCLUSION}

In the light of above mentioned finding, it is concluded that the present study which was conducted under the perspective of structural-functional approach has demonstrated how society and its units are interrelated to meet the needs of the people. It has explained how the isolation of a region has led to the emergence of specific kind of culture of cross-cousin marriages which is unknown in the entire Northern India. There is a belief among the scholars that it might be a Dravidian survival but it couldn't be established because of the lack of evidences. The livelihood of the people depends largely upon agriculture, although a sizeable number of people are employed in government and private sector as well. The family structure show a change towards nuclearity but change is not fast. Cross-cousin marriages are specific in this area and it forms a structure which fulfils the functions of the society. This type of matrimonial alliances brings the solidarity and harmony among the people.

\section{REFERENCES}

[1] Census of India, 2011.

[2] Kane, P. V. (1930). History of Dharmasastra, Puna: Bhanderker Institute Press.

[3] Kapadia, K. M. (1958). Marriage and family in India, Bombay: Oxford University Press.

[4] Levi-Struass, C.L. (1969). The Elementary Structures of Kinship. London: Tavistock.

[5] Ibid.

[6] Consanguinity and its relevance to clinical genetics, National Centre for Biotechnology Information, 2001.

[7] Ahuja \& Ram. (1999). Research Methods, Jaipur: Rawat publications.

[8] Ibid.

[9] Ritzer, Geoger. (2000). Sociological Theory, New Delhi: McGraw Hill.

[10] Kothari, C. R. (2004). Research Methodology; Methods and Techniques, New Delhi: Vishav Prakashan. 